\title{
In vitro Assessment of Intra-operative and Post- operative Environment in Reducing Bladder Cancer Recurrence
}

\section{Ryan Tsz-Hei TSE}

S.H. Ho Urology Centre, Department of Surgery, The Chinese University of Hong Kong, Hong Kong, China.

\section{Hongda ZHAO}

S.H. Ho Urology Centre, Department of Surgery, The Chinese University of Hong Kong, Hong Kong, China.

\section{Christine Yim-Ping WONG}

S.H. Ho Urology Centre, Department of Surgery, The Chinese University of Hong Kong, Hong Kong, China.

\section{Angel Wing-Yan KONG}

S.H. Ho Urology Centre, Department of Surgery, The Chinese University of Hong Kong, Hong Kong, China.

\section{Ronald Cheong-Kin CHAN}

Department of Anatomical and Cellular Pathology, The Chinese University of Hong Kong, Hong Kong, China

\section{Ka-Fai TO}

Department of Anatomical and Cellular Pathology, The Chinese University of Hong Kong, Hong Kong, China

\section{Chi-Fai NG}

S.H. Ho Urology Centre, Department of Surgery, The Chinese University of Hong Kong, Hong Kong, China.

\section{Jeremy Yuen-Chun TEOH ( $\nabla$ jeremyteoh@surgery.cuhk.edu.hk)}

S.H. Ho Urology Centre, Department of Surgery, The Chinese University of Hong Kong, Hong Kong, China.

\section{Research Article}

Keywords: Urinary bladder cancer, surgical resection, mitomycin $\mathrm{C}(\mathrm{MMC})$, sterile water and $\mathrm{MMC}$

Posted Date: June 17th, 2021

DOl: https://doi.org/10.21203/rs.3.rs-618415/v1 
License: (c) (i) This work is licensed under a Creative Commons Attribution 4.0 International License. Read Full License

Version of Record: A version of this preprint was published at Scientific Reports on January 7th, 2022. See the published version at https://doi.org/10.1038/s41598-021-04035-8. 


\section{Abstract}

Urinary bladder cancer is a common cancer worldwide. Currently, the modality of treating and monitoring bladder cancer is wide. Nonetheless, the high recurrence rate of non-muscle-invasive bladder cancer after surgical resection is still unsatisfactory. Hereby, our study demonstrated whether the intra-operative and post-operative environments will affect bladder cancer recurrence utilizing in vitro cell line model. Bladder cancer cell lines were submerged in four different irrigating fluids for assessing their tumorigenic properties. Our results showed that sterile water performed the best in terms of the magnitude of cytotoxicity to cell lines. Besides, we also investigated cytotoxic effects of the four irrigating agents as well as mitomycin $\mathrm{C}(\mathrm{MMC})$ in normothermic and hyperthermic conditions. We observed that sterile water and MMC had an increased cytotoxic effects to bladder cancer cell lines in hyperthermic conditions. Altogether, our results could be translated into clinical practice in the future by manipulating the intraoperative and post-operative conditions in order to lower the chance of residual cancer cell reimplant onto the bladder, which in turns, reducing the recurrence rate of bladder cancers.

\section{1.introduction}

Urinary bladder cancer is the 9th most common cancer in the world. There are more than 550,000 new cases diagnosed and 220,000 deaths every year ${ }^{1,2}$. With the advancement in diagnostic techniques and nonsurgical therapies over the past decades, the treatment and surveillance of bladder cancer have been greatly improved. However, non-muscle-invasive bladder cancer (NMIBC) is still accompanied with high recurrence rate and the prognosis of muscle-invasive bladder cancer (MIBC) has also remained poor ${ }^{3-5}$ which in turns burdening the healthcare system.

Transurethral resection of bladder tumor (TURBT) is the current standard in the initial diagnosis and treatment of NMIBC. Conventionally, monopolar resection in non-conducting intra operative irrigation solutions such as $1.5 \%$ glycine and water, or bipolar resection in isotonic $(0.9 \% \mathrm{NaCl})$ normal saline is commonly performed. Although TURBT is safe and relatively simple to perform, cancer cells can be released during the resection procedure. The floating tumour cells may re-implant to the bladder wall resulting in early disease recurrence ${ }^{6}$. After TURBT, intravesical instillations of chemotherapy such as Mitomycin-C (MMC) can be given to impose a cytotoxic effect on the floating tumour cells. Combining TURBT and an immediate post-operative instillation of chemotherapy can reduce the risk of recurrence by $35 \%{ }^{7}$. In addition, synergism of hyperthermia and chemotherapy is suggested to impose a greater cytotoxic effects to residual cancer cells, therefore, further lower the chance of cancer recurrence after resection.

After resection, the tumour cells will be deprived of blood supply and cell death is an inevitable outcome unless early tumour re-implantation occurs. It was found that human bladder cancer cells form firm attachment onto the culture dish take place within one hour in vitro and reached maximum within 24 hours, followed by proliferation of bladder cancer cells ${ }^{8}$. We believed the condition in vivo maybe similar as in vitro, therefore, it becomes extremely important to understand if the surrounding fluid environment 
has any beneficial or harmful effects on the floating tumour cells. A fluid environment which can avoid tumour re-implantation may be the key in avoiding tumour recurrence after a complete resection.

In this study, we investigated the effects of common irrigating fluids (including $1.5 \%$ glycine, normal saline and water) and mitomycin $\mathrm{C}$, with or without hyperthermia, in terms of tumorigenic properties on four bladder cancer $(\mathrm{CaB})$ cell lines. We believe the results may provide valuable insights on how we can manipulate the fluid environment in order to optimise the oncological outcomes.

\section{Material And Methods Cell lines and reagents}

Four human urinary bladder cancer cell lines (T24, UMUC3, RT4 and HTB9) were used in this study. T24 and RT4 cell lines were maintained in McCoy's 5A Medium with high-glucose and L-glutamine (ThermoFisher Scientific Inc.). UMUC3 and HTB9 were grown in Minimum Essential Medium (MEM) (ThermoFisher Scientific Inc.) and in Roswell Park Memorial Institute (RPMI) 1640 Medium with Lglutamine (ThermoFisher Scientific Inc.) respectively. All the cells were stocked in liquid nitrogen in dimethyl sulfoxide (DMSO) for permanent storage until use. The cell experiments were performed within 40 passages of the cells. After trypsinization, $1 \times 10^{6} \mathrm{~T} 24$, UMUC3, RT4 and HTB9 cells were prepared in suspension with sterile water, normal saline (Baxter), $1.5 \%$ glycine (Baxter), $10 \mu \mathrm{g} / \mathrm{mL}$ MMC (SigmaAldrich, Inc.), $100 \mu \mathrm{g} / \mathrm{mL} \mathrm{MMC}, 1000 \mu \mathrm{g} / \mathrm{mL} \mathrm{MMC}$ or culture media (as controls). Suspension cells in different reagents were incubated at $37^{\circ} \mathrm{C}$ or $43^{\circ} \mathrm{C}$ for 1 hour. Cells were then centrifuged, and cell viability was assessed by $0.4 \%$ Trypan Blue dye exclusion test. Living cells were further tested by four different assays. All the assays were performed in triplicate and at least three independent experiments.

\section{Proliferation assay}

The growth rates of T24, UMUC3, RT4 and HTB9 cells were tested by the proliferation assay. Living cells were first seeded in 96 -well plates $\left(100 \mu \mathrm{l} /\right.$ well) at a density of $1 \times 10^{4}$ cells $/ \mathrm{mL}$. After seeding and incubation for 24 and 48 hours, cells were treated with $10 \mu$ 3-[4,5-dimethylthiazol-2-yl]-2,5diphenyltetrazolium bromide (MTT) (ThermoFisher Scientific Inc.) and incubated for 4 hours. MTTmixture was removed and DMSO was added to dissolve the purple formazan produced by reduction of MTT by living cells and the absorbance was measured at $590 \mathrm{~nm}$ using a microplate reader.

\section{Adhesion assay}

Adhesion assay was performed by plating $2 \times 10^{4}$ cells $/ \mathrm{mL}$ on Gibco ${ }^{\circledR}$ Collagen I-coated plate (ThermoFisher Scientific Inc.). Cells were centrifuged at $71 \mathrm{~g}$ for 5 minutes at room temperature (RT), followed by incubation for 15 minutes at $37^{\circ} \mathrm{C}$ in a humidified incubator with $5 \% \mathrm{CO} 2$. After incubation, media in each well containing cells was then removed and the whole plate underwent centrifugation upside down at $7 \mathrm{~g}$ for 5 minutes at RT. A MTT assay was then performed. After incubation for 4 hours, 
MTT-mixture was removed and DMSO was added, the absorbance at $590 \mathrm{~nm}$ was measured by a microplate reader.

\section{Invasion assay}

Cell invasion assays were carried out using BD BioCoat Matrigel Invasion chambers (BD Biosciences, USA) according to manufacturer's protocol. Briefly, $5 \times 10^{4}$ cells $/ \mathrm{mL}$ living cells were seeded in each transwell containing $0.5 \%$ serum medium. The transwell insert was plated onto the 24 -well plated containing $5 \%$ serum medium as a lower compartment, serving as an attractant for the cells to invade from the upper compartment towards to lower compartment through the microporous Matrigel $\AA^{\circledR}$ matrixreconstituted membrane on the basement of each transwell insert. After incubation at $37^{\circ} \mathrm{C}$ in a humidified incubator with 5\% CO2 for 48 hours, the transwell insert was removed and crystal violet stain was performed, accumulating the cell nuclei of the invasive cells which could enzymatically degrade the Matrigel $\circledast$ matrix and invade through membrane pores to the lower compartment. Stained cells were photographed by an inverted microscope and counted by the Image $\mathrm{J}$ software in three randomly selected fields.

\section{Colony formation assay}

To assess the cell's ability to grow into a colony, 1000 living cells were seeded onto a $100 \mathrm{~mm}$ plate in their respective culture media. The plates were then incubated at $37^{\circ} \mathrm{C}$ in a humidified incubator with $5 \%$ $\mathrm{CO}_{2}$ for 9 days. After the incubation, crystal violet stain was performed, and the living cells were indicated by the total number of stained cell clones on the $100 \mathrm{~mm}$ plates. At least 50 cells were required to define a colony.

\section{Statistical analysis}

Data are plotted as mean \pm standard error of the mean (SEM) at least three independent experiments. Statistical analysis was performed by Student t-test for independent samples with equal variances. The level of significance was set at $p<0.05$ as *, and $p<0.01$ as **.

\section{Results}

\subsection{The effects of normothermic and hyperthermic irrigating fluids on $\mathrm{CaB}$ cell lines}

To evaluate the in vitro cytotoxicity of irrigation fluids, we used intra operative fluids such as water, normal saline and glycine to challenge HTB9, RT4, T24 and UMUC3. Water incubation significantly reduced total number of cells counts in the four $\mathrm{CaB}$ cell lines (Fig. 1A). Normal saline treatment either preserved or promoted cell growth, while water consistently inhibited cell proliferation in HTB9, RT4, T24 and UMUC3 (Fig. 1B). Concerning the adhesion assay, water suppressed adhesion in all four CaB cell lines (Fig. 1C). Similarly, water was able to suppress invasion (Fig. 1D) and colony formation (Fig. 1E) in all four $\mathrm{CaB}$ cell lines. In contrast, normal saline either maintained or stimulated adhesion, invasion and 
clonogenic ability of the four cell lines, and the effects were similar to serum control. $1.5 \%$ glycine had a toxic effect in HTB9; otherwise its effect was largely insignificant in the other three CaB cell lines. Collectively, these results indicate that water is effective in suppressing cell growth and tumor progression, while normal saline does not introduce any adverse effects on cancer cells.

After combining with hyperthermia, we observed that water decreased total number of cells counts in the four CaB cell lines (Fig. 2A). Hyperthermic water suppressed cell proliferation in four cell lines, hyperthermic glycine inhibited cell proliferation in HTB9, T24 and UMUC3, but not RT4; while hyperthermic normal saline promoted cell growth in four cell lines as good as serum control (Fig. 2B). For cell adhesion assay, both hyperthermic water and hyperthermic glycine were able to decrease the cell adhesion ability of the four cell lines (Fig. 2C). Similarly, hyperthermic water and hyperthermic glycine reduced cells invasion (Fig. 2D) and colonies formation (Fig. 2E) in all four CaB cell lines. On the other hand, hyperthermic normal saline promoted cells invasion and clonogenic ability in UMUC3. In summary, our result demonstrated toxic effects of hyperthermic water and hyperthermic glycine on cell proliferation and tumor progression of all four CaB cell lines.

\subsection{The effects of normothermic and hyperthermic MMC on CaB cell lines}

To investigate the cytotoxicity response of hyperthermia drug treatment, we incubated $\mathrm{CaB}$ cells in 10 $\mu \mathrm{g} / \mathrm{ml}, 100 \mu \mathrm{g} / \mathrm{ml}$ or $1000 \mu \mathrm{g} / \mathrm{ml} \mathrm{MMC}$ at $37^{\circ} \mathrm{C}$ or $43^{\circ} \mathrm{C}$ for one hour. We observed that MMC had a dosedependent effect; $1000 \mu \mathrm{g} / \mathrm{ml} \mathrm{MMC}$ at $43^{\circ} \mathrm{C}$ had the most toxic effect against all four $\mathrm{CaB}$ cell lines (Fig. 3A). In contrast, MMC could suppress cell proliferation regardless of concentration and temperature (Fig. 3B). At $37^{\circ} \mathrm{C}$, only $1000 \mu \mathrm{g} / \mathrm{ml} \mathrm{MMC} \mathrm{could} \mathrm{inhibit} \mathrm{cell} \mathrm{adhesion.} \mathrm{Hyperthermia} \mathrm{at} 43^{\circ} \mathrm{C}$ could potentiate the inhibitory effects, and $1000 \mu \mathrm{g} / \mathrm{ml} \mathrm{MMC}$ at $43^{\circ} \mathrm{C}$ was most effective in inhibiting adhesion in all four $\mathrm{CaB}$ cell lines (Fig. $3 \mathrm{C}$ ). In addition, all concentration of $\mathrm{MMC}$ at different temperature significantly restricted invasion (Fig. 3D) and colonies formation (Fig. 3E) in all four CaB cell lines; 1000 $\mu \mathrm{g} / \mathrm{ml} \mathrm{MMC}$ at $43^{\circ} \mathrm{C}$ was the most efficient regimen. In summary, these results suggested that hyperthermic $1000 \mu \mathrm{g} / \mathrm{ml} \mathrm{MMC}$ is the most cytotoxic reagent in $\mathrm{CaB}$ cell lines.

\section{Discussion}

In our study, we investigated the effects of common irrigating fluids and mitomycin C, with or without hyperthermia, on bladder cancer cell lines. Four CaB cell lines in three subtypes, RT4 (luminal), HTB9/5637 (basal) and T24 and UMUC3 (non-type) were used to explore their unique cellular reaction in different culture reagents. We found that water possessed the strongest toxicity to all 4 bladder cancer cell lines, in terms of proliferation, adhesion, invasion and clonal formation. Fechner et al. evaluated the performance of osmotic cytolysis by distilled water and mitomycin to reduce $\mathrm{CaB}$ recurrence. Results show that both distilled water and mitomycin led to significant cell death after 10 minutes to all cell lines. Nonetheless, viability of all cell lines treated with distilled water decreased to $3-5 \%$, yet only 3 out of the 4 cell lines with survival dropped to below $5 \%{ }^{9}$. Together with our study findings, water is shown to have 
strong cytotoxic effects and is promising to prevent bladder cancer cells reimplantation during surgery and recurrence. To explain the phenomenon physically, water is strongly hypotonic to tumor cells, which lack cell wall protection. While surrounding by hypotonic solution, water moves into the cells from outside to balance the concentration on both side of the cells until equilibrium and equal concentration are reached. Therefore, prolong exposure of water may exert cytocidal effects of hypotonic shock to bladder cancer cell lines ${ }^{10}$. In extreme situation, water keeps moving into the cells, destroying normal function, bursting the cells and eventually causing cell death.

On the other hand, our study showed that normal saline possessed a weaker cytotoxic effect, therefore, could hardly prevent the reimplantation of cancer cells. Isotonic normal saline is $0.9 \%(9 \mathrm{~g} / \mathrm{L})$ sodium chloride, having osmolarity around $300 \mathrm{mOsm} / \mathrm{L}$, is closely approximate to the osmolarity of sodium chloride in blood and human cells (about $290 \mathrm{mOsm} / \mathrm{L}$ ). Normal saline is indeed a favorable environment for cancer cells to survive and reimplant to the bladder, which in turn may lead to tumor recurrence. For $1.5 \%$ glycine, our results showed that it had a weaker cytotoxic effects than distilled water. We observed that bladder cancer cell lines maintained proliferation in terms of tumorigenic properties upon glycine irrigation. This demonstrated that $1.5 \%$ glycine may favored cancer cells reimplantation in bladder in vivo after resection. $1.5 \%$ glycine is a weakly ionized solution, contains $15 \mathrm{~g} / \mathrm{L}$ glycine, having osmolarity of $200 \mathrm{mOsmol} / \mathrm{L}$ is slightly hypotonic to normal in vivo physiologic osmolarity condition. The weaker hypotonic property of glycine may explain its limited cytotoxic effect to $\mathrm{CaB}$ cancer cell lines.

To sum up, continuous bladder irrigation with normal saline may in fact potentiate the risk of tumor reimplantation and it should be avoided as far as possible. While water is hypotonic, using it as irrigating fluid during transurethral resection surgery is not ideal due to the risk of transurethral resection syndrome. However, continuous intravesical water irrigation immediately after the surgery can be a cheap but effective method in minimising the risk of tumour reimplantation ${ }^{10-12}$. A comparison between sterile water and $\mathrm{MMC}$ as irrigating agents in vivo after resection was done by Bijalwan et al. Results showed that continuous bladder irrigation with sterile water after resection had comparable results to immediate intravesical MMC in terms of preventing tumor recurrence in NMIBC. Moreover, authors observed sterile water as irrigating agent could reduce adverse effects significantly when compared to MMC instillation. Besides, the recurrence-free rates were both low for sterile water-treated and MMC-treated groups though the study had a small sample size ${ }^{13}$.

To further investigate the cytotoxic effects induced by irrigating fluids under hyperthermia, we repeated the proliferation assay, cell adhesion assay, invasion assay and colonies formation assay on the four $\mathrm{CaB}$ cell lines at $43^{\circ} \mathrm{C}$. Similar to our results in the normothermic experiments, the strongest cytotoxicity was observed in water under hyperthermic condition. Water as a strong hypotonic fluid, its toxicity effect was maintained under high temperature on cell growth and other cancer properties in four all cell lines tested. Our result also showed that hyperthermia could increase the in vitro toxicity of glycine on all cell lines. Treating cells in $43^{\circ} \mathrm{C}$ glycine for one hour could greatly suppress cell adhesion, invasion and colonies formation in HTB9, RT4, T24 and UMUC3. Hyperthermia alone can induce protein unfolding, ROS generation and DNA replication and repair alteration, eventually causes cell death ${ }^{14}$. Besides, direct 
cytotoxicity associated with heat exposure is related to exposure time. It was shown that one hour exposure at $43^{\circ} \mathrm{C}$ induced a large extent of irreversible cytotoxicity, $30 \%$ more cell death ${ }^{15}$, therefore, it was expected that the cytotoxicity to $\mathrm{CaB}$ cell lines induced by water and glycine were at least similar or even higher under hyperthermiac condition. Intriguingly, our results showed that hyperthermia in saline did not affect cytotoxicity as in water and glycine. In fact, upon hyperthermic saline resulted in an attenuated inhibition to 2 out of $4 \mathrm{CaB}$ cell lines, T24 and UMUC3, in terms of invasion and colony formation. T24 and UMUC3 both belong to non-type CaB cell lines (Warrick JI 2016) under molecular characterization, and the mechanism behind this diverse response of hyperthermic normal saline to T24 and UMUC3 is uncertain and need further examination.

Intravesical maintenance chemotherapy is a standard treatment for patients with NMIBC. Although it shows a lower rate of adverse events, its treatment efficacy has been proven to be inferior to intravesical BCG therapy, especially for high-risk NMIBC patients. In recent years, people have developed deviceassisted technology which can enhance chemotherapy efficiency. MMC is a naturally occurring bioreductive alkylating agent that attacks and destroys cancerous cells, and the standard clinical concentration is $1000 \mathrm{ug} / \mathrm{ml}$ in final volume $20 \mathrm{ml}$ to be instilled into bladder for an hour incubation. However, we found that $1000 \mathrm{ug} / \mathrm{ml} \mathrm{MMC}$ under normothermic condition could not significantly reduce cell adhesion ability of non-typing cells, T24 and UMUC3. Cell adhesion plays a pivotal role in cancer progression and metastasis. Hyperthermia has been shown to boost the efficacy of cytotoxic agent treatments. Malignant cancerous cells are also more heat sensitive than normal cells or tissues ${ }^{16}$. From our results, we demonstrated that hyperthermia at $43^{\circ} \mathrm{C}$ in synergy with $\mathrm{MMC}$ resulted in a stronger cytotoxic effect to all $4 \mathrm{CaB}$ cancer cell lines than $\mathrm{MMC}$ treatment in $37^{\circ} \mathrm{C}$. On the other hand, we observed $\mathrm{MMC}$ concentration of $1000 \mathrm{ug} / \mathrm{mL}$ exhibited the strongest inhibition in proliferation and cancer properties of the four $\mathrm{CaB}$ cell lines. One explanation to the our observations is that tumor cells may uptake higher amount of $\mathrm{MMC}$ and are less resistant to the drugs under hyperthermia treatment. Besides, MMC may have increase cytotoxic activities under higher temperatures, as heat can destroy cell membrane fluidity, weaken or denature cellular proteins, losing protein function will eventually causing decrease in proliferation and increase in apoptosis of cancer cells. Our results supported the use of hyperthermic chemotherapy in the clinical setting to optimise the oncological outcomes of NMINC following TURBT.

\section{Limitations}

Our study investigated the intra-operative and post-operative intravesical environment in preventing $\mathrm{CaB}$ cell lines reimplantation. The cytotoxic effects of water as an irrigation agent to $\mathrm{CaB}$ cancer cell lines, and the synergistic effect of hyperthermia and MMC in inhibiting proliferation of cancer cells in vitro were explored. The results are promising in translating into clinical studies and applications. Nonetheless, there are also some limitations in our study. First of all, our results on the in vitro setting might not be replicated in the in vivo setting. Further investigations using animal models could be considered before translating into clinical practice ${ }^{9}$. Secondly, the mechanisms underlying the synergistic effects of 
hyperthermia and $\mathrm{MMC}$ in different cancer cell lines require further investigations. The synergistic effects may vary depending on the concentrations of $M M C$ and the type of cell lines being tested. In our results, UMUC-3 exhibited the greatest drug resistance towards MMC, even under hyperthermia treatment, in terms of immediate toxicity effects. Thirdly, although the $\mathrm{CaB}$ cell lines utilized represented different stages and grades of bladder tumor, they are still limited in mimicking the in vivo conditions. For example, cell lines cannot illustrate the interactions between bladder tumor and surrounding cells. Besides, morphology and physiological parameters may alter when passaging cancer cells on plastic surface, for example, losing polarity, which may affect our study results. Moreover, prolong culture may cause genetic drift which may have effects on their tumorigenic properties. Therefore, more advance models should be considered before applying our results in clinical practices. For example, 3D organoid cultures serve as a better to mimic cell-cell interactions as well as to elaborate a more detail human body environment. Further studies can be applied on immortalized cell line derived-organoid or even patient primary tumorderived organoid models to validate our results.

\section{Conclusion}

Urinary bladder cancer is a common cancer in worldwide. Currently TURBT is the standard to resect NMIBC tumor, however, accompany with high recurrence rate. Hereby, we investigated intra-operative and post-operative environments in reducing bladder cancer recurrence. In our study, we investigated the cytotoxic effects of different irrigating fluids to $\mathrm{CaB}$ cell lines, in terms of tumorigenic properties. Our results demonstrated that water is the most cytotoxic agents to $\mathrm{CaB}$ cell lines when compared to glycine and saline, which could only barely killing cancer cells or even maintained their tumorigenic properties. We further investigated the synergic effects of hyperthermia and irrigating agents as well as MMC. Our results demonstrated that water still possessed the highest cytotoxic effects to $\mathrm{CaB}$ cell lines under hyperthermic condition among the three irrigating agents that we tested. Besides, synergism among hyperthermia and MMC also exhibited high efficacy in killing cancer cells. Our results are promising in studying how different conditions, during resection and after surgery, may contributed to bladder cancer recurrence. Nonetheless, further experiments should be carried out, for instance, xenograft models, before translating our results into clinical settings.

\section{References}

1 Bray, F. et al. Global cancer statistics 2018: GLOBOCAN estimates of incidence and mortality worldwide for 36 cancers in 185 countries. CA Cancer J Clin 68, 394-424, doi:10.3322/caac.21492 (2018).

2 Teoh, J. Y. et al. Global Trends of Bladder Cancer Incidence and Mortality, and Their Associations with Tobacco Use and Gross Domestic Product Per Capita. Eur Urol 78, 893-906, doi:10.1016/j.eururo.2020.09.006 (2020). 
Krajewski, W. et al. Impact of Adjuvant Chemotherapy on Survival of Patients with Advanced Residual Disease at Radical Cystectomy following Neoadjuvant Chemotherapy: Systematic Review and Meta-Analysis. J Clin Med 10, doi:10.3390/jcm10040651 (2021).

4 Krajewski, W. et al. Delaying BCG immunotherapy onset after transurethral resection of nonmuscle-invasive bladder cancer is associated with adverse survival outcomes. World J Urol, doi:10.1007/s00345-020-03522-3 (2020).

5 Sylvester, R. J. et al. European Association of Urology (EAU) Prognostic Factor Risk Groups for Non-muscle-invasive Bladder Cancer (NMIBC) Incorporating the WHO 2004/2016 and WHO 1973 Classification Systems for Grade: An Update from the EAU NMIBC Guidelines Panel. Eur Urol, doi:10.1016/j.eururo.2020.12.033 (2021).

6 Soloway, M. S. \& Masters, S. Urothelial susceptibility to tumor cell implantation: influence of cauterization. Cancer 46, 1158-1163, doi:10.1002/1097-0142(19800901)46:5<1158::aidcncr2820460514>3.0.co;2-e (1980).

7 Sylvester, R. J. et al. Systematic Review and Individual Patient Data Meta-analysis of Randomized Trials Comparing a Single Immediate Instillation of Chemotherapy After Transurethral Resection with Transurethral Resection Alone in Patients with Stage pTa-pT1 Urothelial Carcinoma of the Bladder: Which Patients Benefit from the Instillation? Eur Urol 69, 231-244, doi:10.1016/j.eururo.2015.05.050 (2016).

8 Pode, D., Alon, Y., Horowitz, A. T., Vlodavsky, I. \& Biran, S. The mechanism of human bladder tumor implantation in an in vitro model. J Uro/ 136, 482-486, doi:10.1016/s0022-5347(17)44926-3 (1986).

9 Fechner, G., Pocha, K., Schmidt, D. \& Muller, S. C. Reducing recurrence and costs in superficial bladder cancer: preclinical evaluation of osmotic cytolysis by distilled water vs. mitomycin. Int J Clin Pract 60, 1178-1180, doi:10.1111/j.1742-1241.2006.00847.x (2006).

10 Matsuoka, Y., Taoka, R., Xia, Z., Sugimoto, M. \& Kakehi, Y. Hyperthermic therapy using warm sterile water enhances cytocidal effects on bladder cancer cells. Scand J Uro/ 54, 65-69, doi:10.1080/21681805.2019.1708967 (2020).

11 Sangeda, R. Z. et al. Prevention of tumor cell reimplantation during transurethral resection: the invitro antiadhesive and cytotoxic properties of an irrigant containing polyethylene glycol 400. Anticancer Drugs 21, 645-650, doi:10.1097/CAD.0b013e32833a148d (2010).

12 Taoka, R., Williams, S. B., Ho, P. L. \& Kamat, A. M. In-vitro cytocidal effect of water on bladder cancer cells: The potential role for intraperitoneal lavage during radical cystectomy. Can Urol Assoc J 9 , E109-113, doi:10.5489/cuaj.2435 (2015).

13 Bijalwan, P., Pooleri, G. K. \& Thomas, A. Comparison of sterile water irrigation versus intravesical mitomycin $\mathrm{C}$ in preventing recurrence of nonmuscle invasive bladder cancer after transurethral resection. 
Indian J Uro/ 33, 144-148, doi:10.4103/iju.IJU_371_16 (2017).

14 Roti Roti, J. L. Cellular responses to hyperthermia (40-46 degrees C): cell killing and molecular events. Int J Hyperthermia 24, 3-15, doi:10.1080/02656730701769841 (2008).

15 Rampersaud, E. N., Vujaskovic, Z. \& Inman, B. A. Hyperthermia as a treatment for bladder cancer. Oncology (Williston Park) 24, 1149-1155 (2010).

16 van der Heijden, A. G. et al. The effect of hyperthermia on mitomycin-C induced cytotoxicity in four human bladder cancer cell lines. Eur Uro/ 46, 670-674, doi:10.1016/j.eururo.2004.06.009 (2004).

\section{Figures}



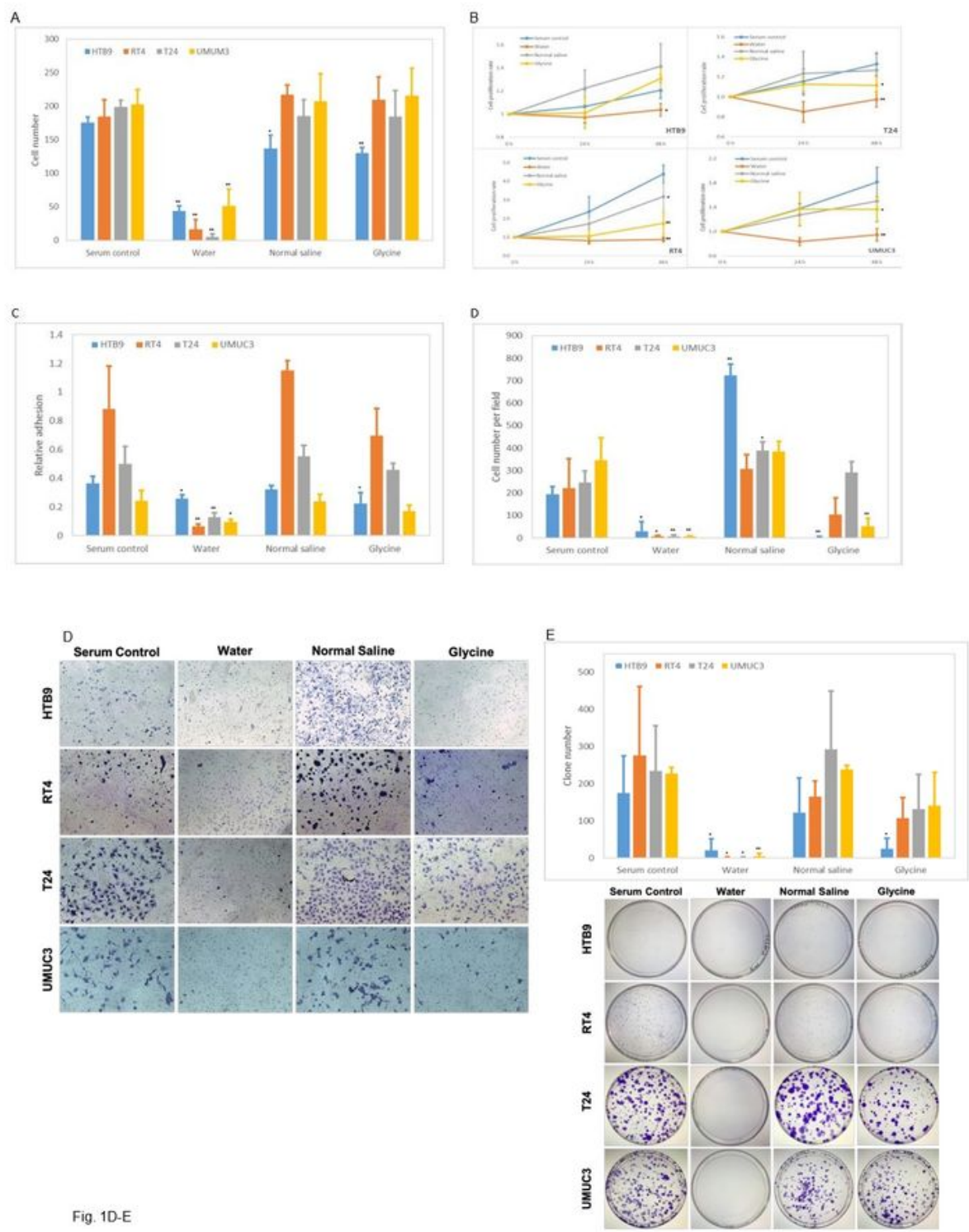

\section{Figure 1}

Identification of potential cytotoxicity of irrigation fluids. (A) Bladder cancer cell lines HTB9, RT4, T24 and UMUC3 were incubated in water, normal saline or glycine for one hour. Total cell counts were quantified by trypan blue exclusion assay. (B) Cell proliferation rates were measured by MTT assays and presented as relative fold change to 0 hour. (C) Cell adhesion ability were evaluated by measuring the attached cells by MTT assays and OD reading was proportional to the number of adhered cells. (D) Cell invasion assays 
were used to evaluate invasion capacity using the Matrigel invasion chambers. Cells invaded through the Matrigel layer were stained by crystal violet and counted using the Image J software. (E) Colonies formation abilities were determined by seeding 1000 living cells onto a $100 \mathrm{~mm}$ plate and incubated for 9 days. Colonies were then stained with crystal violet and colonies with more than 50 cells were counted. Data are presented as the mean $\pm S D$. Different strategies were compared with serum control of the same cell line. ${ }^{*} p<0.05$ and ${ }^{* \star} p<0.01$, $t$ test $(n=3$, three independent biological replicates were performed for all the assays).
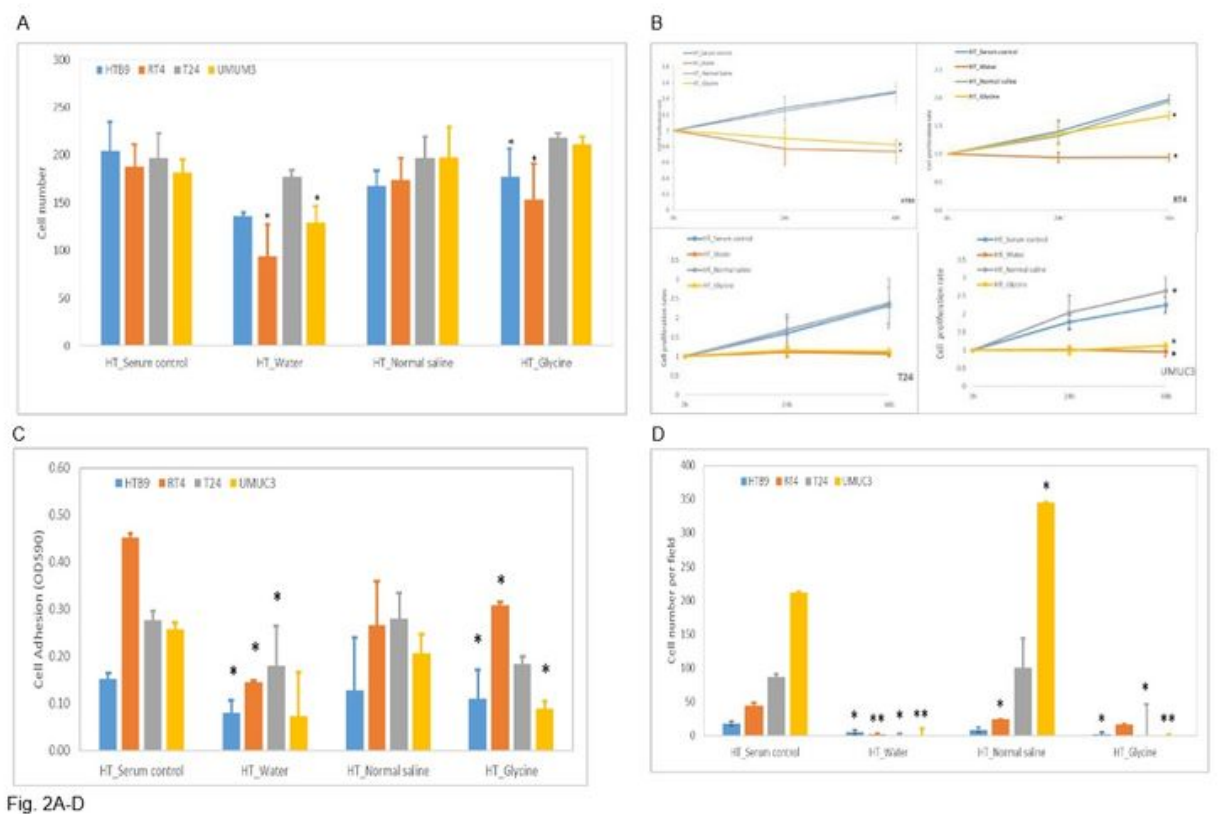

Fig. 2A-D
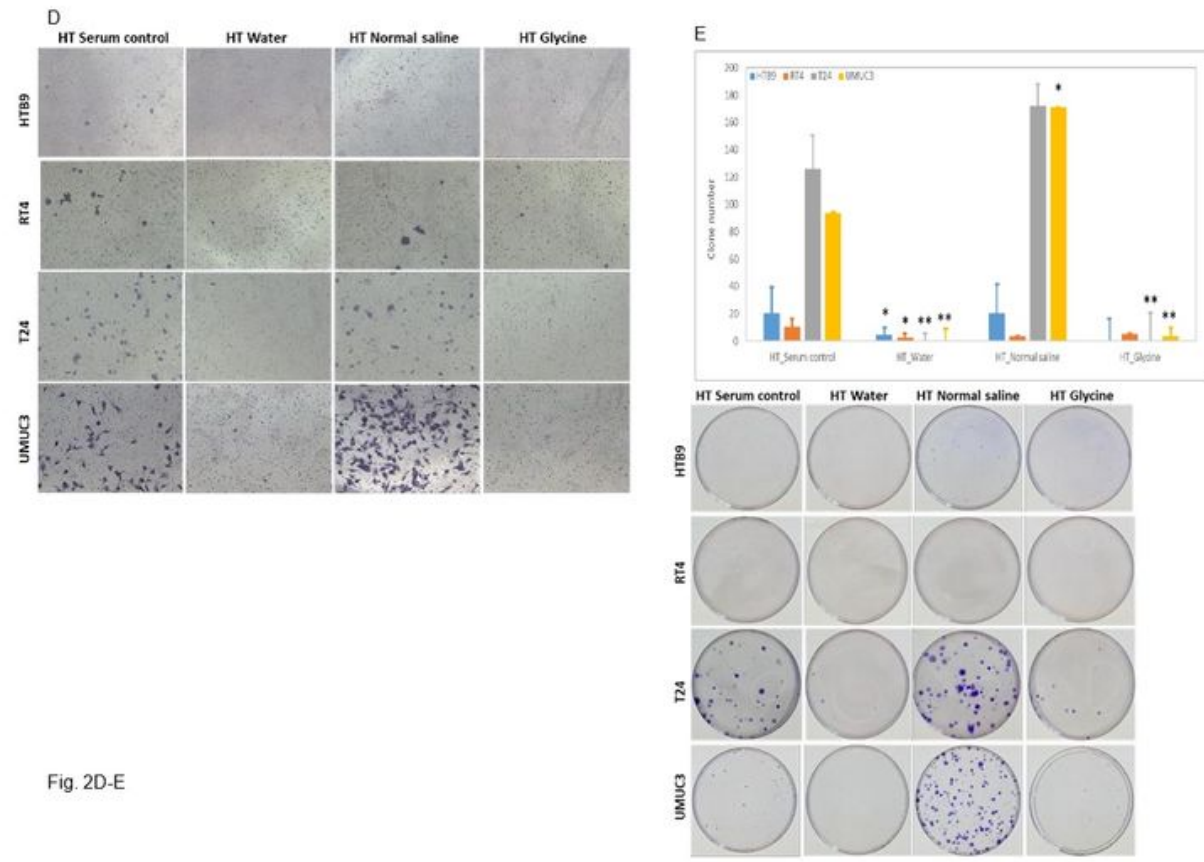


\section{Figure 2}

Cytotoxicity of combining hyperthermia and irrigation fluids. (A) HTB9, RT4, T24 and UMUC3 were incubated in water, normal saline or glycine at $43^{\circ} \mathrm{C}$ for one hour. Total cell counts were estimated by trypan blue exclusion assays. (B) Cell proliferation rates were measure by MTT assays and presented as relative fold change to 0 hour. (C) Adhesion assay were evaluated by MTT assays as OD reading was proportional to number of adhered cells. (D) Invasion ability was evaluated by Matrigel gel transwell chambers. Cells with invasion ability were measured by crystal violet staining and cell counting. (E) Colonies formation ability was assayed by crystal violet staining and cell counting. Data are presented as mean \pm SD. Different strategies were compared with serum control of the same cell line. ${ }^{*} p<0.05$ and ${ }^{*} p$ $<0.01$, $t$ test $(n=3$, three independent biological replicates were performed for all the assays). 

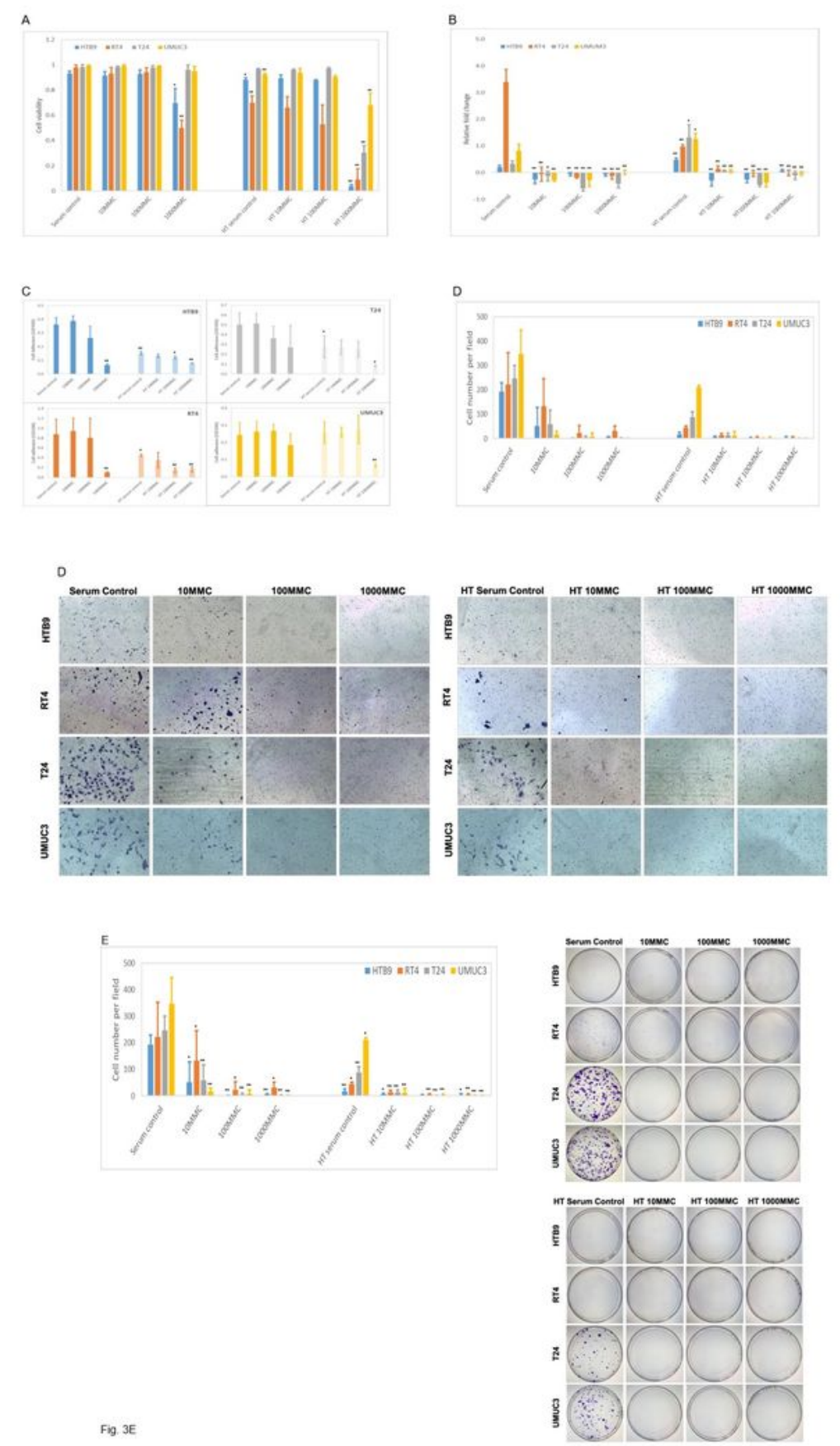

\section{Figure 3}

Hyperthermic Mitomycin-C markedly inhibits proliferation and tumor character of $\mathrm{CaB}$ cells. (A) Cytotoxicity of MMC was tested on bladder cancer cell lines at different concentration, $10 \mu \mathrm{g} / \mathrm{ml}$, $100 \mu \mathrm{g} / \mathrm{ml}$ and $1000 \mu \mathrm{g} / \mathrm{ml} ;$ at $37^{\circ} \mathrm{C}$ and $43^{\circ} \mathrm{C}$. Total cell counts were calculated by trypan blue exclusion assays after drug incubation. Cell viability was evaluated and presented as percentage of living cells. (B) Growth suppression was measured by MTT assays and expressed as relative fold change at end point of 
48 hours. (C) Adhesion assays were measured by MTT assays and OD reading was proportional to the number of adhered cells. (D) Matrigel invasion abilities were evaluated by crystal violet staining and cell counting. (E) Colonies formation assays were performed by staining the cell clones with crystal violet. Colony with more than 50 cells was counted. Data are presented as the mean \pm SD. $37^{\circ} \mathrm{C}$ treatments and $43^{\circ} \mathrm{C}$ serum control were compared with $37^{\circ} \mathrm{C}$ serum control of the same cell line, and $43^{\circ} \mathrm{C}$ treatments were compared with $43^{\circ} \mathrm{C}$ serum control of the same cell line. ${ }^{*} p<0.05$ and ${ }^{* *} p<0.01$, $t$ test $(n=3$, three independent biological replicates were performed for all the assays). 